Published in final edited form as:

Am J Obstet Gynecol. 2019 July ; 221(1): 67.e1-67.e12. doi:10.1016/j.ajog.2019.02.030.

\title{
A Contemporary Amniotic Fluid Volume Chart for the United States: The NICHD Fetal Growth Studies-Singletons
}

\author{
John OWEN, MD, MSPH ${ }^{1}$, Paul S. ALBERT, PhD ${ }^{2}$, Germaine M. BUCK LOUIS, PhD, MS $^{2}$, \\ Karin M. FUCHS, MD ${ }^{3}$, William A. GROBMAN, MD, MBA ${ }^{4}$, Sungduk KIM, PhD ${ }^{2}$, Mary E. \\ D'ALTON, MD ${ }^{3}$, Ronald WAPNER, MD ${ }^{3}$, Deborah A. WING, MD, MBA ${ }^{5}$, and Katherine L. \\ GRANTZ, MD MS ${ }^{2}$ \\ ${ }^{1}$ University of Alabama at Birmingham, Center for Women's Reproductive Health \\ 2Eunice Kennedy Shriver National Institute of Child Health and Human Development, National \\ Institutes of Health, Bethesda, MD \\ ${ }^{3}$ Columbia University Medical Center, New York, NY \\ ${ }^{4}$ Northwestern University, Chicago, IL \\ 5University of California, Irvine, Miller Children's Hospital/Long Beach Memorial Medical Center, \\ Orange, CA
}

\section{Abstract}

Background-Amniotic fluid is essential to normal fetal development and is estimated clinically with ultrasound to identify pregnancies at risk for poor perinatal outcome,

Objectives: Our goal was to develop a United States standard for amniotic fluid volume estimated by the amniotic fluid index and single deepest pocket.

Study Design-We performed a planned secondary analysis of a multicenter observational study of 2334 low-risk women with normal singleton gestations from one of 4 self-reported racial-ethnic groups. Eligible women had confirmed first-trimester dating criteria with health status, lifestyles and medical and obstetric histories associated with normal fetal growth. Consenting women underwent serial (up to 5) sonographic evaluations of amniotic fluid between 15 and 40 weeks' gestation after being randomly assigned to one of 4 gestational age observation schedules. Twelve

Corresponding author: John Owen, MD, MSPH, Department of Obstetrics and Gynecology, Maternal-fetal Medicine Division, The University of Alabama at Birmingham School of Medicine, 176F 10270L, $61919^{\text {th }}$ St South, Birmingham, AL 35249-7333, Tel: 205-934-7343Fax: 205-975-9858, jowen@uabmc.edu.

Drs. Albert and Kim are currently at the NCI Division of Cancer Epidemiology and Genetics, Bethesda, MD

Dr. Buck Louis is currently at George Mason University, Office of the Dean, Fairfax, VA

Dr. Wing is currently at Korn Ferry, Los Angeles, CA

Publisher's Disclaimer: This is a PDF file of an unedited manuscript that has been accepted for publication. As a service to our customers we are providing this early version of the manuscript. The manuscript will undergo copyediting, typesetting, and review of the resulting proof before it is published in its final citable form. Please note that during the production process errors may be discovered which could affect the content, and all legal disclaimers that apply to the journal pertain.

Disclosure: Deborah A. Wing has been a consultant for Parsogen, for which she received no compensation. The other authors did not report any potential conflicts of interest.

Reprints will not be available.

Presented in abstract form at the annual meeting of the Society for Maternal-Fetal Medicine, Las Vegas, NV, January 23-28, 2017 
U.S. perinatal centers participated, and all sonograms were performed by credentialed sonographers using identical, high-resolution equipment; caregivers were unaware of results but were notified for oligohydramnios. Women $(\mathrm{N}=597)$ subsequently found to have clinically significant antepartum complications were excluded. Racial-ethnic-specific nomograms for amniotic fluid index and single deepest pocket across gestation were developed using linear mixed models with cubic splines, while racial-ethnic differences were evaluated both with global and between-group tests. Median, $3^{\text {rd }}, 5^{\text {th }}, 10^{\text {th }}, 90^{\text {th }}, 95^{\text {th }}$ and $97^{\text {th }}$ percentile values were also estimated. We further considered the possible confounding effects of selected maternal characteristics and the estimated fetal weight at each sonogram.

Results-A total of 1719 pregnant women met inclusion criteria and had available data. These included 480 non-Hispanic white, 418 non-Hispanic black, 485 Hispanic and 336 Asian women. Both the amniotic fluid index and the single deepest pocket varied across gestation with maximal values at 26 and 33 weeks respectively. Statistically significant differences were observed by maternal race-ethnicity. The between-group differences observed at 17-22 weeks' and 35-40 weeks' gestation remained statistically significant after adjusting for maternal characteristics and estimated fetal weight. These between-group racial-ethnic differences were most prominent after 35 weeks' gestation and at the extremes of dispersion ( $3^{\text {rd }}$ and $97^{\text {th }}$ percentiles). All $3^{\text {rd }}$ and $97^{\text {th }}$ percentile amniotic fluid index values were within the range of commonly used cutoffs to define oligohydramnios ( $\leq 5 \mathrm{~cm}$ ) and polyhydramnios ( $\geq 25 \mathrm{~cm}$ ). However, $3^{\text {rd }}$ percentile values ranged between $5.9 \mathrm{~cm}$ at 40 weeks and $10.1 \mathrm{~cm}$ at $25-27$ weeks, while the $97^{\text {th }}$ percentile values ranged between $24.8 \mathrm{~cm}$ at 38 weeks and $15.7 \mathrm{~cm}$ at 15 weeks.

Conclusions-Sonographic amniotic fluid volume estimates vary by racial-ethnic group, but the absolute differences appear to be small and may not be clinically significant. Selected maternal characteristics and estimated fetal weight did not affect the racial-ethnic differences. Betweengroup differences are maximal after 35 weeks and at the extremes of the upper and lower dispersion estimates. Given the observed variability in extreme ( $3^{\text {rd }}$ and $97^{\text {th }}$ percentile) dispersion values over gestation, use of single cutoffs to define out-of-range measurements may not be clinically appropriate. These data might form a contemporary United States standard for amniotic fluid estimation using the amniotic fluid index and the single deepest pocket.

\section{ClinicalTrials.gov Identifier for parent study: NCT00912132}

\section{Keywords}

Amniotic fluid volume estimate; Amniotic fluid index; Largest vertical pocket; Single deepest pocket; Fetal growth; Estimated fetal weight; Low-risk; Ethnic; Racial

\section{INTRODUCTION}

Amniotic fluid is essential to normal fetal development, particularly the pulmonary and musculoskeletal systems; it also provides umbilical cord protection ${ }^{1}$. Since amniotic fluid volume (AFV) abnormalities are associated with perinatal pathology, estimation of AFV is a standard part of obstetric sonography ${ }^{2}$. As an indicator of fetal well-being, it is commonly used as a part of antepartum fetal surveillance as a component of both the modified and complete biophysical profile ${ }^{3}$. It is also used in the evaluation of pregnancies for complications such a premature membrane rupture, twin-twin transfusion syndrome and 
fetal congenital anomalies. Well-established methods for estimating AFV include the 4quadrant amniotic fluid index (AFI) and the single deepest pocket (SDP), both reproducible semi-quantitative techniques, although the visual subjective estimate of an experienced sonographer has also been utilized ${ }^{2}$.

To date there has been no published sonographic AFV standard for U.S. women. Previously published nomograms of sonographically estimated AFV across gestation ${ }^{4-15}$ have been limited by retrospective, cross-sectional design or uneven representation of measurements across gestation ${ }^{4,10,14,15}$, small sample size which affects precision, especially of dispersion estimates $^{5,11,14}$, and study populations not representative of the current diverse U.S. population $^{5-8,11-13}$. Essentially all nomograms were developed from sonographers who were aware of women's clinical status, while indications for the examinations may not have been specifically for AFV estimation; both are factors which could bias the observations. Most reports also lacked simultaneous estimates of both AFI and SDP which prevent a comparison of these 2 techniques, especially at the extremes of fluid volumes. Moreover, although ultrasound technology has improved markedly in the past 2 decades there have been few recent evaluations of AFV across gestation. The possible confounding effects of selected maternal characteristics and estimated fetal size on AFV measurements have also not been well-studied ${ }^{16-19}$ and not included in the development of essentially all published $^{4-15}$. Finally, current nomograms were not developed from populations selected to have maternal characteristics associated with normal fetal growth, and reasonably, amniotic fluid production.

Our primary goal was to develop standard AFI and SDP charts for U.S. women and secondarily to assess the association of race-ethnicity with these values, while also estimating the association of other maternal characteristics and fetal weight.

\section{MATERIALS and METHODS}

This is a planned secondary analysis of the NICHD Fetal Growth Studies-Singletons, a large-scale, multi-center prospective observational cohort study whose primary goal was to develop U.S. racial-ethnic standards for fetal growth from 10 to 41 weeks' gestation ${ }^{20}$. Investigators at the 12 clinical sites enrolled 2334 gravidas between July, 2009 and January, 2013, from 4 self-reported racial-ethnic groups with optimal characteristics for normal fetal growth. These characteristics included maternal age 18-40 years, body mass index 19-29.9 $\mathrm{kg} / \mathrm{m}^{2}$, and normal obstetric and medical histories. Human subjects' approval was obtained from all clinical sites and women gave informed consent prior to data collection. After enrollment, only women with an uncomplicated pregnancies were retained and analyzed for the growth standard and also for this analysis $(\mathrm{N}=1737)$. Additional specific details about inclusion and exclusion criteria are detailed in the primary report of the parent study ${ }^{20}$ along with a complete description of the cohort's design and methodology ${ }^{21}$.

Before consent, all participants underwent a first trimester ultrasound that confirmed a certain last menstrual period (LMP) date. The ultrasound estimate of gestation had to be between $8+0$ weeks and $13+6$ weeks and also match the LMP-based gestational age within 5 days for women between $8+0$ and $10+6$ weeks, within 6 days for those between 
$11+0$ weeks and $12+6$ weeks and within 7 days for participants between $13+0$ and $13+6$ weeks for continued participation in the study. With these criteria satisfied, the project gestational age was based on the menstrual date. Women were then assigned at random to one of 4 sonography schedules as shown in the box to ensure that data were available at each $( \pm 1)$ week of gestation without subjecting women to weekly obstetrical ultrasounds between 16 and 26 weeks and at each week of gestation starting at 28 weeks:

\section{Sonology}

At each study sonogram, credentialed sonographers measured standard fetal biometrics used for the fetal growth standard and also measured the AFV using both the 4-quadrant $\mathrm{AFI}^{22}$ and the SDP techniques ${ }^{23}$ using Voluson E8 machines (GE Healthcare, Milwaukee, WI) and multifrequency curvilinear transducers (real-time abdominal 4-8 MHz). Because AFV measurements began at $<20$ weeks, the sonographers were trained to divide the uterus into 4 quadrants along the sagittal plane and a point half-way to the fundus ${ }^{10}$. The face of the ultrasound transducer was aligned parallel to the floor with the patient supine. Additional fetal biometric measurements were obtained and estimated fetal weight (EFW) was calculated using the measured fetal head circumference, abdominal circumference, and femoral length with a Hadlock formula ${ }^{24}$.

All study protocol examinations were performed independent of any clinically-indicated scans, which also may have been performed per usual clinical practice by the managing physicians. Findings from the study protocol examinations were revealed to managing physicians in cases of severe oligohydramnios, defined as a SDP $<2 \mathrm{~cm}$ or an AFI $<5 \mathrm{~cm}$. All images and measurement data were captured in Viewpoint (GE Healthcare, Milwaukee, WI) and electronically transferred to the data coordinating center. Prior to and during the trial, ultrasound quality was assessed by ante hoc training and credentialing of all site sonographers and a protocol for post hoc quality assurance that included a central review of a random sample of all scans ${ }^{25}$.

\section{Statistics}

Baseline and clinical data were compared for participants by women's self-reported raceethnicity using Chi-square or t-tests for categorical and continuous data, respectively. AFI and SDP percentiles $\left(3^{\text {rd }}, 5^{\text {th }}, 10^{\text {th }}\right.$, median, $90^{\text {th }}, 95^{\text {th }}$, and 97 th $)$ were estimated using linear mixed models with cubic splines as fixed effects and cubic terms as random effects corresponding to gestational age. Cubic splines were used to provide a very flexible representation of the trajectories of AFI and SDP across gestational age ${ }^{26}$. Three knot points were chosen for the cubic splines at gestational ages that evenly split the distributions $\left(25^{\text {th }}\right.$, $50^{\text {th }}$ and $75^{\text {th }}$ percentiles). We a priori chose the knots at the three quartile cut points based on each biomarker distribution, as this yields an equal number of measurements within each region separated by the knot points. We chose three since our experience has suggested that the underlying trajectories were rather smooth over gestational age and choosing a larger number of knots resulted in unstable trajectories. Both AFI and SDP values were logtransformed to stabilize variances across gestational age and to improve normal approximations for the error structures. Percentiles were estimated based on the assumed normal distribution of the random effects and error structure. Estimated percentile AFI and 
SDP curves were first developed across gestation from the $15^{\text {th }}$ to the $40^{\text {th }}$ weeks of gestation for the entire population.

Because of the statistically significant racial-ethnic differences in fetal growth observed in the entire study population ${ }^{20}$, we next evaluated whether AFI and SDP differed by maternal race-ethnicity (4 groups). We further controlled for the effects of selected maternal characteristics and we finally considered the potential effect of the log-transformed estimated fetal weight (EFW) at each examination. Selected maternal covariates were assessed as a group and included: age, height, weight, parity, full time employment versus student status, marital status (married, living as married versus not), insurance (private, managed versus Medicaid versus other), income, education, and infant sex (male versus female). Annual income and education were analyzed categorically: income $<\$ 30,000$; $\$ 30,000-\$ 39,999 ; \$ 40,000-\$ 49,999 ; \$ 50,000-\$ 74,999 ; \$ 75,000-\$ 99,999 ; \$ 100,000$ and education: < high school, high school or equivalent, some college or associate degree, bachelor degree versus master's or higher degree.

Differences among the race-ethnicity groups were evaluated with a global test (i.e. likelihood-ratio test) that examined whether there were any differences in the longitudinal mean fluid volume profiles across the 4 groups. These tests were conducted separately for AFI and SDP, where the global p-value was used to identify any statistically significant differences using the threshold of $\mathrm{p}<0.05$. If the global $\mathrm{p}$-value was found to be statistically significant, we further identified gestational-age-week-specific differences using Wald tests which compared differences among race-ethnic groups at each week of gestation. The Wald tests were first conducted by comparing means across all four groups, and then by forming pairwise tests to compare differences between the racial-ethnic groups at each week of gestation.

All analyses were done with and without collective covariate adjustments (covariates listed previously). We used multiple imputations to account for missing covariate information ${ }^{27}$. We empirically assessed model validity using simulation analysis to ensure unbiased percentile estimates and compared different mixed model cubic splines, cubic polynomials and second order fractional polynomials, individual-specific interpolation and smoothing methods $^{28-29}$. All analyses were implemented using SAS (version 9.4, SAS Institute, Inc., Cary, North Carolina) or R (version 3.1.2, http://www.R-project.org).

\section{RESULTS}

Due to missing AFV data, 1,719 of the 1,737 (99.6\%) pregnancies included in the fetal growth standard ${ }^{20}$ were included in the AFV standard analyses. The final study population included 480 non-Hispanic white (NHW), 418 non-Hispanic black (NHB), 485 Hispanic (H) and 336 Asian (A) women. Maternal characteristics are shown in Table 1. Asian women had the highest mean maternal age, and Hispanic women had the highest prepregnancy BMI and the highest rate of multiparity. The observed differences in gestational ages at the initial and final ultrasound, though statistically significant, were not clinically important. Notably, birth gestational ages were similar across the 4 groups. Marital status, family income, medical insurance and employment showed significant intergroup differences with NHW having the 
highest rates of marriage, college education, high income, private insurance and full-time employment in comparison to other racial-ethnic groups of mothers.

Unadjusted overall population AFI and SDP standard nomograms by gestational week are shown in Figures $1 \& 2$ respectively. Median AFI increased from 15 weeks, peaked at 26 weeks, and then underwent a slight but steady decrease through 40 weeks. In contrast, median SDP steadily increased until 33 weeks, remaining relatively constant from 33 to 37 weeks, after which there was a slight decline. Unadjusted overall population median and percentile AFI and SDP values by gestational week are also presented in Tables $2 \& 3$ respectively. We confirmed that the variances did not vary by GA on the log-transformed scale utilized ${ }^{30}$. Further, our percentiles explicitly accounted for the estimation done in the random effects models by increasing the variability accordingly.

Figure 3 is a graph that depicts the relative magnitude of median AFI and SDP weekly changes throughout gestation from 15 to 40 weeks as estimated by the weekly percent change. Note that small percent changes (near zero on the Y-axis) might not be obviously reflected in tables $2 \& 3$ because of rounding. For AFI, median values increased at an accelerated rate until approximately 17 weeks when the weekly increase began to slow and level off at approximately 26 weeks marking its peak. After this time, median AFI began to decrease slowly with a more pronounced decrease beginning at approximately 35 weeks. Compared to AFI, changes in the SDP demonstrated a similar overall pattern, but with a delayed timing of the changes. For example, the AFI percent change reached zero at 26 weeks compared to the initial SDP zero change at 27 weeks. However, the SDP underwent another slight increase between 27 and 33 weeks with a second stable peak between 33 and 37 weeks.

As shown in Table 2, the $5^{\text {th }}$ percentile for AFI was above $7 \mathrm{~cm}$ until 40 weeks when it fell to $6.4 \mathrm{~cm}$. The $95^{\text {th }}$ percentile for AFI was always below $23 \mathrm{~cm}$ and it stayed between 21 and $22 \mathrm{~cm}$ for 11 weeks from 24 to 34 weeks. When we assessed the most extreme values for AFI, the $3^{\text {rd }}$ percentile remained 6 or greater through 39 weeks falling to $5.9 \mathrm{~cm}$ at 40 weeks. Conversely, the $97^{\text {th }}$ percentile AFI values increased over gestation attaining values of $24.7 \mathrm{~cm}$ at 39 weeks and $24.1 \mathrm{~cm}$ at 40 weeks. Depicted in Table 3, the $3^{\text {rd }}$ percentile for SDP was at least $2 \mathrm{~cm}$ for every gestational week studied. The $97^{\text {th }}$ percentile for SDP increased from $5.1 \mathrm{~cm}$ at 15 weeks to $8.8 \mathrm{~cm}$ at 39 weeks; at 40 weeks it fell slightly to 8.7 $\mathrm{cm}$.

Median AFI curves (Figure 4) differed by race-ethnicity (global $P<0.001$ ), with weekspecific differences at 17-22 weeks' and 35-40 weeks' (all $P<0.05$ ) that remained significant after adjusting for maternal characteristics and EFW (all Wald p-values $<0.05$ ). Similarly, as depicted in Figure 5, race-ethnicity affected SDP (global $P<0.001$ ), with weekspecific differences at 16-21 weeks' and 36-40 weeks' (all Wald p-values $<0.05$ ). Although statistically significant inter racial-ethnic differences were observed, the absolute median differences were generally very small. For example in the 35-40 week range the greatest difference was observed at 40 weeks where NHW had the largest $(13.4 \mathrm{~cm})$ and NHB the smallest $(11.9 \mathrm{~cm})$ unadjusted median AFI values, but the absolute difference was only 1.5 
$\mathrm{cm}$. In the 17-22 week range, the maximum differences among the cohorts were no more than $1.1 \mathrm{~cm}$.

Graphs of median and both extreme ( $3^{\text {rd }}$ and $\left.97^{\text {th }}\right)$ percentiles of AFI and SDP for each racial-ethnic group by gestational week are shown in Figures $4 \& 5$ respectively. For both AFI and SDP the racial-ethnic associations on the median and extreme dispersion values were most pronounced after 35 weeks, where maximum intergroup differences at the $3^{\text {rd }}$ and especially the $97^{\text {th }}$ percentiles were almost $5 \mathrm{~cm}$ by 40 weeks. Overall the $3^{\text {rd }}$ percentile values demonstrated less variation in absolute AFI and SDP values compared to the $97^{\text {th }}$ percentiles; NHW patients had the highest $97^{\text {th }}$ percentile AFI values after 27 weeks but only after 37 weeks did their $97^{\text {th }}$ percentile SDP values exceed the other groups. Conversely, NHB patients had larger $97^{\text {th }}$ percentile AFI and SDP values from 16 to 25 weeks.

Adding the maternal characteristics, as described above, to the AFI and SDP models which informed figures 1-5 and tables 1-2, had no appreciable effect on the racial-ethnic differences, since the global p-values remained significant and the week-specific differences were essentially unchanged (data not shown). Similarly, additionally adjusting for EFW had no discernable effect on the observed racial-ethnic differences (data not shown), indicating that these AFV differences were not explained by previously identified racial-ethnic differences in fetal growth over gestation ${ }^{21}$.

\section{COMMENT}

\section{Principal findings}

We present AFI and SDP median, percentiles and graphical nomograms based on controlled data observed in a large contemporary multiracial-ethnic cohort of U.S. women with lowrisk singleton gestations. Study participants underwent serial sonographic measurements of AFI and SDP from 15-40 weeks' gestation using up-to-date, high resolution ultrasound equipment. Women included in the analysis were selected initially to have characteristics that would be anticipated to support normal fetal growth and reasonably, amniotic fluid production. The population was further refined by the exclusion of pregnancy complications. We observed statistically significant differences in both AFI and SDP across the 4 racialethnic groups, even after adjustment for selected maternal characteristics and the sonographic estimated fetal weight. The $3^{\text {rd }}$ percentile for AFI was greater than $5.0 \mathrm{~cm}$ and for SDP it was greater than $2.0 \mathrm{~cm}$ at every gestational week. Conversely, while polyhydramnios is often defined as $\geq 24 \mathrm{~cm}$ or SDP $>8 \mathrm{~cm}$, in our cohort the $97^{\text {th }}$ percentile for AFI was less than $24 \mathrm{~cm}$ through 35 weeks of gestation and for SDP it was less than 8.0 $\mathrm{cm}$ through 33 weeks of gestation. Perhaps the most pervasive observation is that the $97^{\text {th }}$ percentile in normal pregnancies varies markedly across gestation: $16 \mathrm{~cm}$ at 15 weeks versus $24 \mathrm{~cm}$ after 35 weeks.

There was observed racial-ethnic variance in the $3^{\text {rd }}$ percentile values notable after 35 weeks, although the absolute differences were smaller than those seen at the $97^{\text {th }}$ percentile. Hispanic and NHW women had values closest to the overall mean, while NHB women had 
approximately a one $\mathrm{cm}$ smaller value, and NHB women had a one $\mathrm{cm}$ greater value; this represented the largest race-ethnic differences, which was maximal at 40 weeks.

The best interpretation of the small observed differences in weekly percent changes between the AFI \& SDP (figure 3) is unclear. The one week delay in the initial SDP "zero" change compared to the AFI is likely of no biologic relevance and could easily represent inherent differences in AFV estimation. Single deepest pocket is akin to a one-dimensional estimate, whereas AFI may be more analogous to a two-dimensional measurement. Thus one might not expect perfect concordance between the two estimates. As a single dimensional estimate, SDP may also be more influenced by the enlarging fetal size which would affect its estimate to a larger degree than a 4-quadrant estimate; this might explain its second (though modest increase in its peak value) between 33 and 37 weeks.

\section{Meaning of the findings/Clinical implications}

We believe that our data should not be used to establish absolute clinical thresholds which define pathologically diminished or increased amniotic fluid volumes because they were derived from a normal, referent population. Our findings of marked differences in the extremes of AFV across gestation may belie the use of a single AFV estimate to define oligohydramnios or polyhydramnios; while all AFI values at $<35$ weeks were below the commonly used cutoff of $24 \mathrm{~cm}^{2}$, there were marked differences in the $97^{\text {th }}$ percentiles across gestation. Similarly, the $3^{\text {rd }}$ percentile values varied across gestation but with a much smaller range in absolute measurement differences.

An important question is whether our observed racial-ethnic differences in amniotic fluid volume, most evident at the percentile extremes, near or at term, are clinically important. Considering the upper $97^{\text {th }}$ percentile, at term, NHW women exceeded the other group values by several $\mathrm{cm}$, while $\mathrm{H}$ and $\mathrm{A}$ women had the lowest measurements. These racialethnic differences, though not as pronounced, were also evident in the GVP. The etiology for the racial-ethnic differences in AFV is unclear, but, surprisingly, was not explained by observed racial-ethnic differences in fetal growth as estimated using sonographic fetal weight. Thus, use of race-ethnic-specific values, while feasible, might not improve the value of surveillance and might represent an unnecessary burden to implement in clinical practice.

\section{Strengths and weaknesses}

Major strengths of the study include the ability to report measured AFI and SDP medians and other percentiles in a low-risk cohort comprised of 4 racial-ethnic groups representative of the current U.S. population. Moreover, women were subsequently excluded if clinically significant pregnancy complications that were known to affect growth were discovered based on a priori criteria applied before the study results were released. Only experienced, credentialed sonographers made these measurements; AFV was a specific parameter required for credentialing. All sonograms were performed for research purposes and the findings were not used for clinical management; however, in cases of severe oligohydramnios, this was reported. This may have led to a repeat measurement and other testing or interventions by the managing providers. Regardless, the measured AFV values from that scan would have been included in our analysis. 
As with any measurement protocol, interobserver variation can affect the findings; however this concept has been investigated and considered to be small ${ }^{10,32}$ and consistent across studies ${ }^{33}$. Although inter-rater and intra-rater reliability for AFV was not formally tested in the Fetal Growth Study accreditation process ${ }^{25}$, it was deemed excellent for the fetal biometrics. Thus we have no reason to believe that this would have been different for AFV measurement. Although interobserver variability is a well-recognized limitation to essentially all biologic research where more than one observer measures a biometric parameter, use of multiple sonographers would increase the external validity of our study compared to a single observer. Nevertheless, the variability in SDP estimation may be greater as compared to $\mathrm{AFI}^{34}$ while the use of sonographic estimates to accurately diagnose oligohydramnios remain a concern ${ }^{1}$.

Measurements were performed at perinatal centers well-known for clinical investigations; the ultrasound equipment was also standardized across the 12 clinical centers. The AFV measurement procedures were well-defined in the original study protocol, and these techniques have been well-standardized and in common clinical use for nearly 3 decades. Participants were randomly assigned to one of 4 different sonography schedules to ensure that measurements across the entire gestational range were performed and available for analysis. We utilized statistical models that optimized the utility of these repeated measures and further considered possible covariate effects beyond race-ethnicity.

\section{Conclusion with future research implications}

Although various cut-points to define abnormal AVF (i.e. oligo- or polyhydramnios) have been published, the best cut-points to identify pregnancies with increased risk of neonatal morbidity, especially in cases of isolated oligohydramnios, remain uncertain ${ }^{31}$. Therefore, investigators should first establish reference charts in a low risk, diverse population of patients selected to have characteristics associated with normal fetal growth and fetal urine production. The observed racial-ethnic differences could not be explained by selected maternal characteristics or estimated fetal weight. We believe that these differences should not be considered clinically relevant until further investigation demonstrates that inclusion of these differences as part of clinical management leads to measurable improvements in pregnancy outcomes.

In summary, compared to previous studies of amniotic fluid volume estimates using the AFI and GVP across gestation, we believe that he strengths of our study design, execution and analysis overcome essentially all of the limitations present in previous reports of sonographically estimated amniotic fluid volume across gestation and thus could represent a legitimate U.S. standard for sonographic amniotic fluid volume. Importantly, these values should not necessarily dictate clinical action points, but rather we suggest that they inform future research into the clinical implications and management of suspected amniotic fluid abnormalities. For example, the finding of an AFV estimate at the extreme might reasonably indicate the need for closer fetal surveillance that might include a subsequent (specialized) evaluation or the institution of more formal fetal surveillance (e.g. biophysical profile). Also given the observed variation in the dispersion extremes across gestation, use of single value 
cutoffs to define out-of-range measurement estimates may not be appropriate, although this possibility will require further investigation as well.

\section{ACKNOWLEDGEMENTS}

The authors acknowledge the research teams at all participating clinical centers, including Christina Care Health Systems, University of California, Irvine, Long Beach Memorial Medical Center, Northwestern University, Medical University of South Carolina, Columbia University, New York Presbyterian Queens, Queens, St. Peters' University Hospital, University of Alabama at Birmingham, Women and Infants Hospital of Rhode Island, Fountain Valley Regional Hospital and Medical Center, and Tufts University. The authors also acknowledge C-TASC and The EMMES Corporations in providing data and imaging support for this multi-site study. This work would not have been possible without the assistance of GE Healthcare Women's Health Ultrasound for their support and training on the Voluson and Viewpoint products over the course of this study.

Funding: This research was supported by the Intramural Research Program of the Eunice Kennedy Shriver National Institute of Child Health and Human Development, National Institutes of Health (Contract Numbers: HHSN275200800013C; HHSN275200800002I; HHSN27500006; HHSN275200800003IC; HHSN275200800014C; HHSN275200800012C; HHSN275200800028C; HHSN275201000009C)

\section{References}

1. Moore TR. The role of amniotic fluid assessment in evaluating fetal well-being. Clin Perinatol. 2011 3;38(1):33-46. [PubMed: 21353088]

2. American College of Obstetricians and Gynecologists and the American Institute of Ultrasound in Medicine Ultrasound in Pregnancy. Practice Bulletin No. 175. Obstet Gynecol 2016; 128:e241-56. [PubMed: 27875472]

3. American College of Obstetricians and Gynecologists. Antepartum fetal surveillance. Practice Bulletin No. 145. Obstet Gynecol 2014; 124:182-92. [PubMed: 24945455]

4. Hallek M, Kirshon B, Smith EO, Cotton D. Amniotic fluid index: gestational age-specific values for normal human pregnancy. J Reprod Med 1993;38:853-6. [PubMed: 8277480]

5. Hinh ND, Ladinsky JL. Amniotic fluid index measurements in normal pregnancy after 28 gestational weeks. Intl J Gynecol Obstet. 2005;91:132-6.

6. Jeng CJ, Jou TJ, Wang KG, Yang YC, Lee YN, Lan CC. Amniotic fluid index measurement with the four-quadrant techniques during pregnancy. J Reprod Med 1990;35:674-7. [PubMed: 2198348]

7. Lei $\mathrm{H}$, Wen SW for the central-south china fetal growth study group. Normal amniotic fluid index by gestational week in a Chinese population. Obstet Gynecol 1998;92:237-40. [PubMed: 9699758]

8. Machado MR, Cecatti JG, Krupa F, Faundes A. Curve of amniotic fluid index measurements in lowrisk pregnancy. Acta Obstetricia et Gynecologica, 2008;86:37-41.

9. Magann EF, Sanderson M, Martin JN, Chauhan SP. The amniotic fluid index, single deepest pocket and two-diameter pocket in normal human pregnancy. Am J Obstet Gynecol 2000;182:1581-8. [PubMed: 10871481]

10. Moore TR, Cayle JE. The amniotic fluid index in normal human pregnancy. Am J Obstet Gynecol 1990 5;162(5):1168-73. [PubMed: 2187347]

11. Nwosu EC, Welch CR, Manasse PR, Walkinshaw SA. Longitudinal assessment of aniotic fluid index. Br J Obstet Gynecol 1993;100:816-9.

12. Peixoto AB, da Cunha Caldas TM, Giannecchini CV, Rolo LC, Martins WP, Araujo E Júnior. Reference values for the single deepest vertical pocket to assess the amniotic fluid volume in the second and third trimesters of pregnancy. J Perinat Med. 2016-A 8 1;44(6):723-7. [PubMed: 26495922]

13. Peixoto AB, Caldas TM, Martins WP, Da Silva Costa F, Araujo E Júnior. Unconditional reference values for the amniotic fluid index measurement between 26w0d and 41w6d of gestation in lowrisk pregnancies. J Matern Fetal Neonatal Med. 2016-B 10;29(20):3243-8. [PubMed: 26586609]

14. Phelan JP, Ahn MO, Smith CV, Rutherford, SE, Anderson E. Amniotic fluid index measurements during pregnancy. J Reprod Med 1987-A;32:601-4. [PubMed: 3309290] 
15. Phelan JP, Smith CV, Broussard P, Small M. Amniotic fluid volume assessment with the fourquadrant technique at 36-42 weeks' gestation. J Reprod Med 1987-B;32:540-2. [PubMed: 3305930]

16. Perni SC, Predanic M, Cho JE, et al. Association of amniotic fluid index with estimated fetal weight. J Ultrasound Med 2004;23:1449-52. [PubMed: 15498909]

17. Owen P, Osman I, Farrell T. Is there a relationship between fetal weight and amniotic fluid index? Ultrasound Obset Gynecol 2002;20:61-3.

18. Wadnere N, Kosta S, Kumar R. Association between fetal weight and amniotic fluid index in women of Central India. Adv Biomed Res. 2014;3:243. [PubMed: 25538929]

19. Prior T, Mullins E, Bennett P, Kumar S. Influence of parity on fetal hemodynamics and amniotic fluid volume at term. Ultrasound Obstet Gynecol. 2014 12;44(6):688-92. [PubMed: 24585483]

20. Buck Louis GM, Grewal J, Albert PS, Sciscione A, Wing DA, Grobman WA, Newman RB, Wapner R, D’Alton ME, Skupski D, Nageotte MP, Ranzini AC, Owen J, Chien EK, Craigo S, Hediger ML, Kim S, Zhang C, Grantz KL. Racial/ethnic standards for fetal growth: the NICHD Fetal Growth Studies. Am J Obstet Gynecol. 2015; 213(4):449.e1-449.e41. [PubMed: 26410205]

21. Grewal J, Grantz K, Zhang C, Scisione A, Wing DA, Grobman WA, Newman RB, Wapner R, D'Alton ME, Skupski D, Nageotte MP, Ranzini AC, Owen J, Chien EK, Craigo S, Albert PS, Kim S, Hediger ML, Buck Louis GM. Cohort profile: NICHD fetal growth studies-singleton and twins. Int J Epi 2017; 9 8:1-13.

22. Rutherford SE, Phelan JP, Smith CV, Jacobs N. The four-quadrant assessment of amniotic fluid volume. I. The relationship of marginal and decreased amniotic fluid volumes to perinatal outcomes. Obstet Gynecol 1987-A;70:353-6. [PubMed: 3306497]

23. Chamberlain PF, Manning FA, Morrison I, Harman CR, Lange IR. Ultrasound evaluation of amniotic fluid volume I. The relationship of marginal and decreased amniotic fluid volumes to perinatal outcomes. Am J Obstet Gynecol 1984;150:245-9. [PubMed: 6385713]

24. Hadlock FP, Harrist RB, Sharman RS, Deter RL, Park SK. Estimation of fetal weight with the use of head, body and femur measurements-a prospective study. Am J Obstet Gynecol 1985;151:3337. [PubMed: 3881966]

25. Hediger ML, Fuchs KM, Grantzet al. Ultrasound quality assurance (QA) for singletons in the NICHD fetal growth studies. J Ultrasound Med 2016;35:1725-33. [PubMed: 27353072]

26. Villandre L, Hutcheon JA, Trejo ME, Abenhaim H, Jacobsen G, and Platt RW. Modeling fetal weight for gestational age: a comparison of a flexible multi-level spline-based model with other approaches. International Journal of Biostatistics-Article 32. 2011;7:1-26.

27. Sterne JA, White IR, Carlin JB, et al. Multiple imputation for missing data in epidemiological and clinical research: potential and pitfalls. BMJ 2009;338:b2393. [PubMed: 19564179]

28. Royston P, Altman D, Regression using fractional polynomials of continuous covariates. JRSS Series C 1994;43:429-67.

29. Cleveland WS. LOWESS: a program for smoothing scatter plots by robust locally weighted regression. Am Stat 1981;35:54.

30. Altman DC, Chitty LS. Charts of fetal size: 1. Methodology. BJOG 1994; 101(1):29-34.

31. Sherer DM. A review of amniotic fluid dynamics and the enigma of isolated oligohydramnios. Am J Perinatol 2002;19:253-66. [PubMed: 12152144]

32. Rutherford SE, Smith CV, Phelan JP, Kawakami K, Ahn MO. Four-quadrant assessment of amniotic fluid volume-interobserver and intraobserver variation. J Reprod Med 1987-B;8:587-9.

33. Chang TC, Yeo SH, Huang HF, Leng JH. Reproducibility of the amniotic fluid index: its effect on clinical practice. Ultrasound Obstet Gynecol 1995; 6:416-20. [PubMed: 8903917]

34. Williams K, Wittman B, Dansereau J. Intraobserver reliability of amniotic fluid volume estimation by two techniques: amniotic fluid index vs. maximum vertical pocket. Ultrasound Obstet Gynecol 1993;3:346-9. [PubMed: 12797259] 


\section{Condensation}

Sonographic amniotic fluid volume estimates vary by gestational age and racial-ethnic group; selected maternal characteristics and estimated fetal weight did not affect the racial-ethnic differences. 


\section{AJOG at a Glance:}

A. To develop a United States standard for sonographic estimation of amniotic fluid volume using the amniotic fluid index and single deepest pocket.

B. A total of 1,719 low-risk women from 4 self-reported racial-ethnic groups and with normal pregnancy outcomes, underwent serial assessments of amniotic fluid from 15-40 weeks' gestation as part of an NICHD-funded, multicenter prospective observational study. Small but statistically significant racial-ethnic differences were identified. After controlling for selected maternal characteristics and estimated fetal weight, these racialethnic differences persisted, but may not be clinically relevant.

C. Compared to previously developed amniotic fluid-gestational age nomograms, these data represent significant improvements in multiple aspects of study design and execution and could represent a legitimate U.S. standard. 


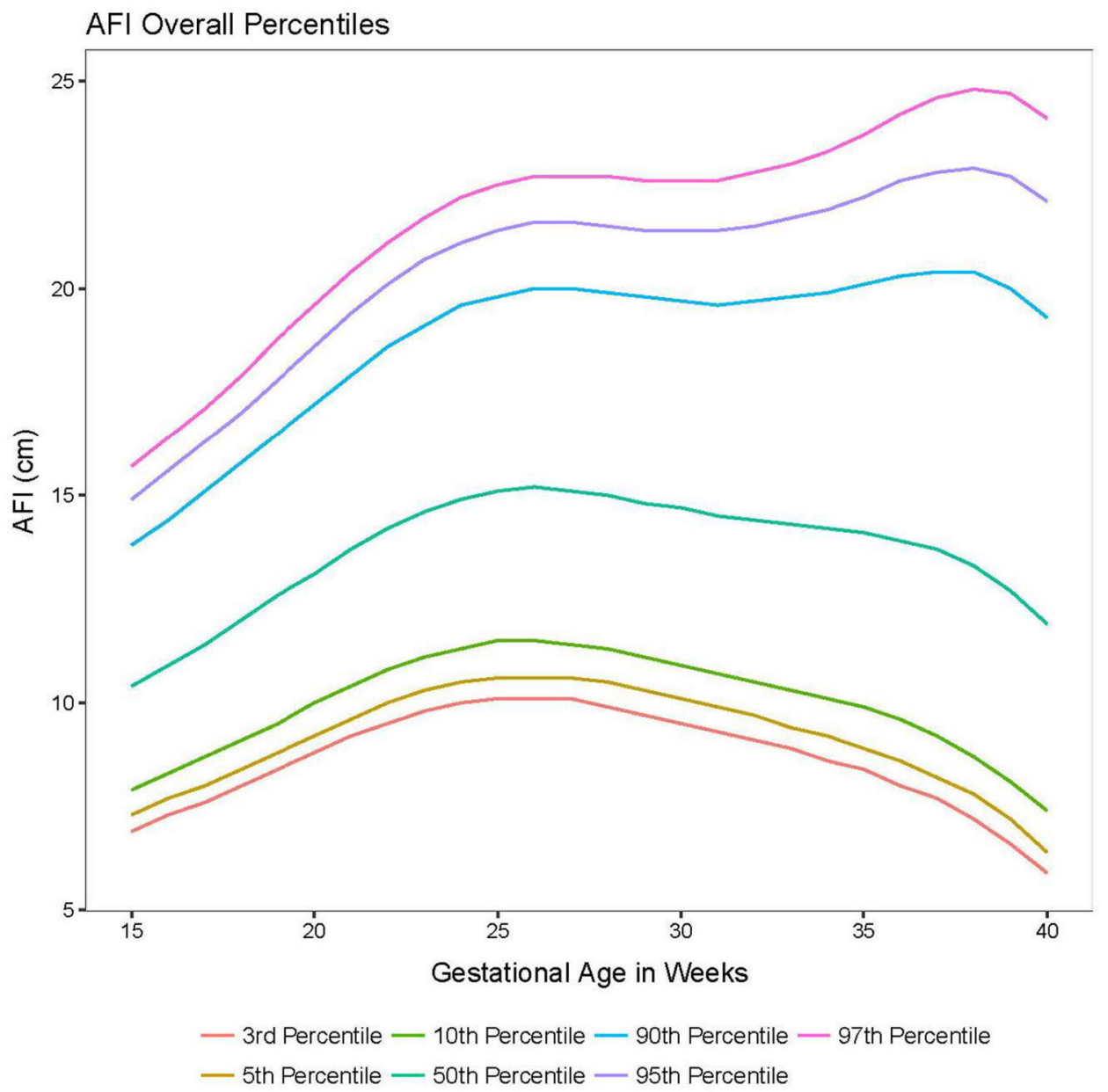

Fig. 1.

Unadjusted amniotic fluid index (AFI) values and percentiles by weeks of gestation (combined race-ethnicities) 


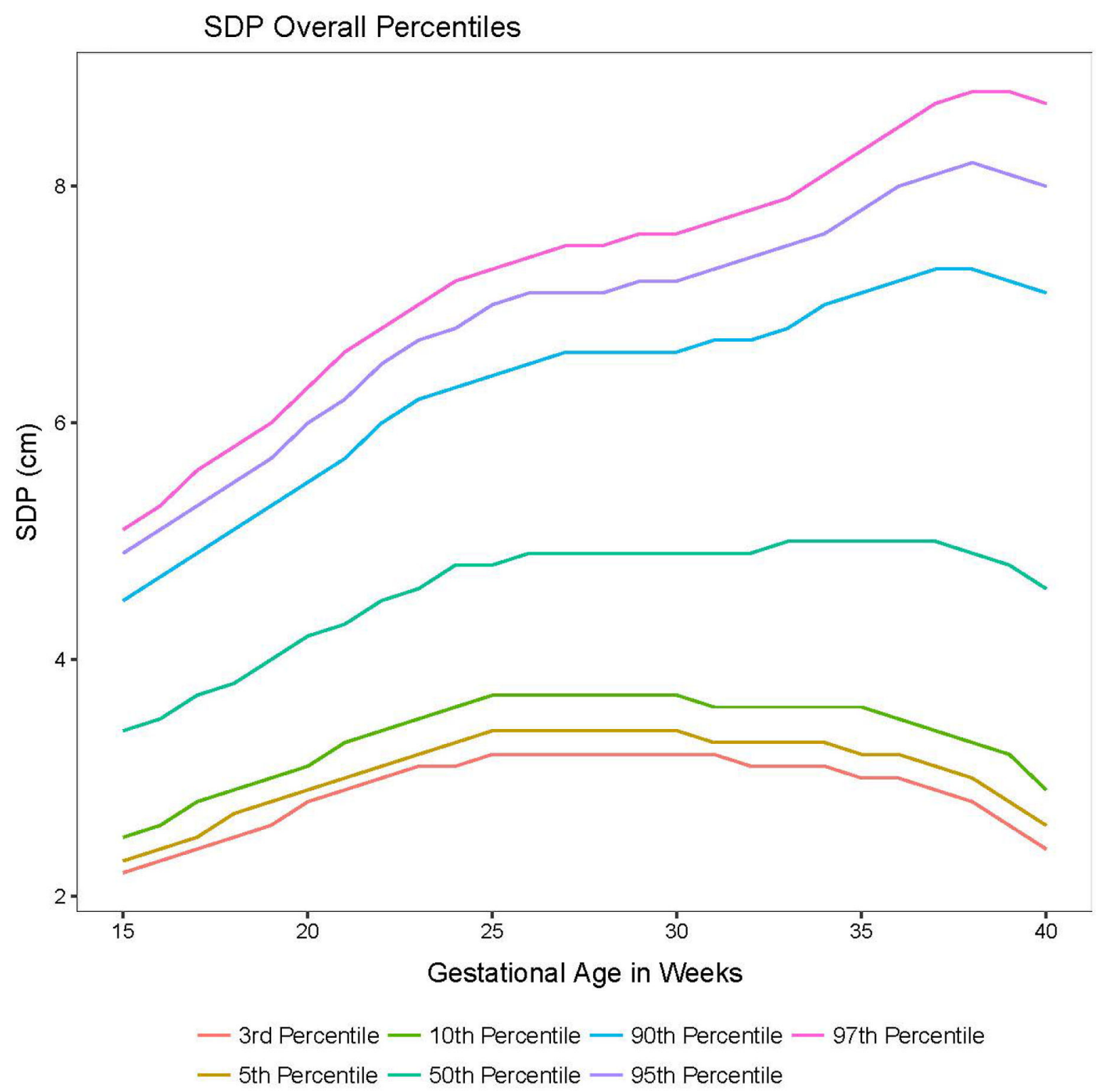

Fig. 2.

Unadjusted single deepest pocket (SDP) values by weeks of gestation (combined raceethnicities). 

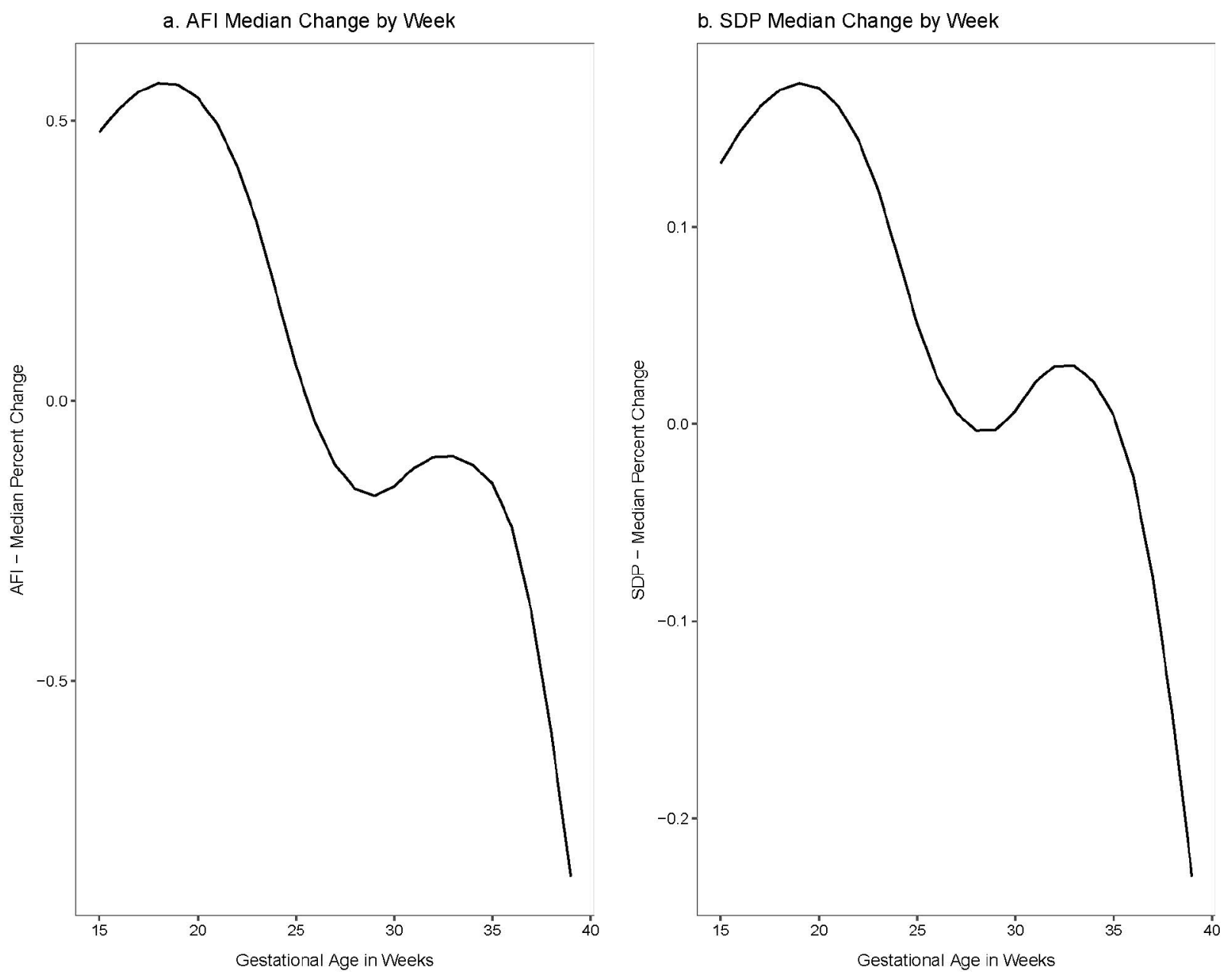

Fig 3.

Percent weekly change in amniotic fluid index (AFI) and single deepest pocket (SDP) values 


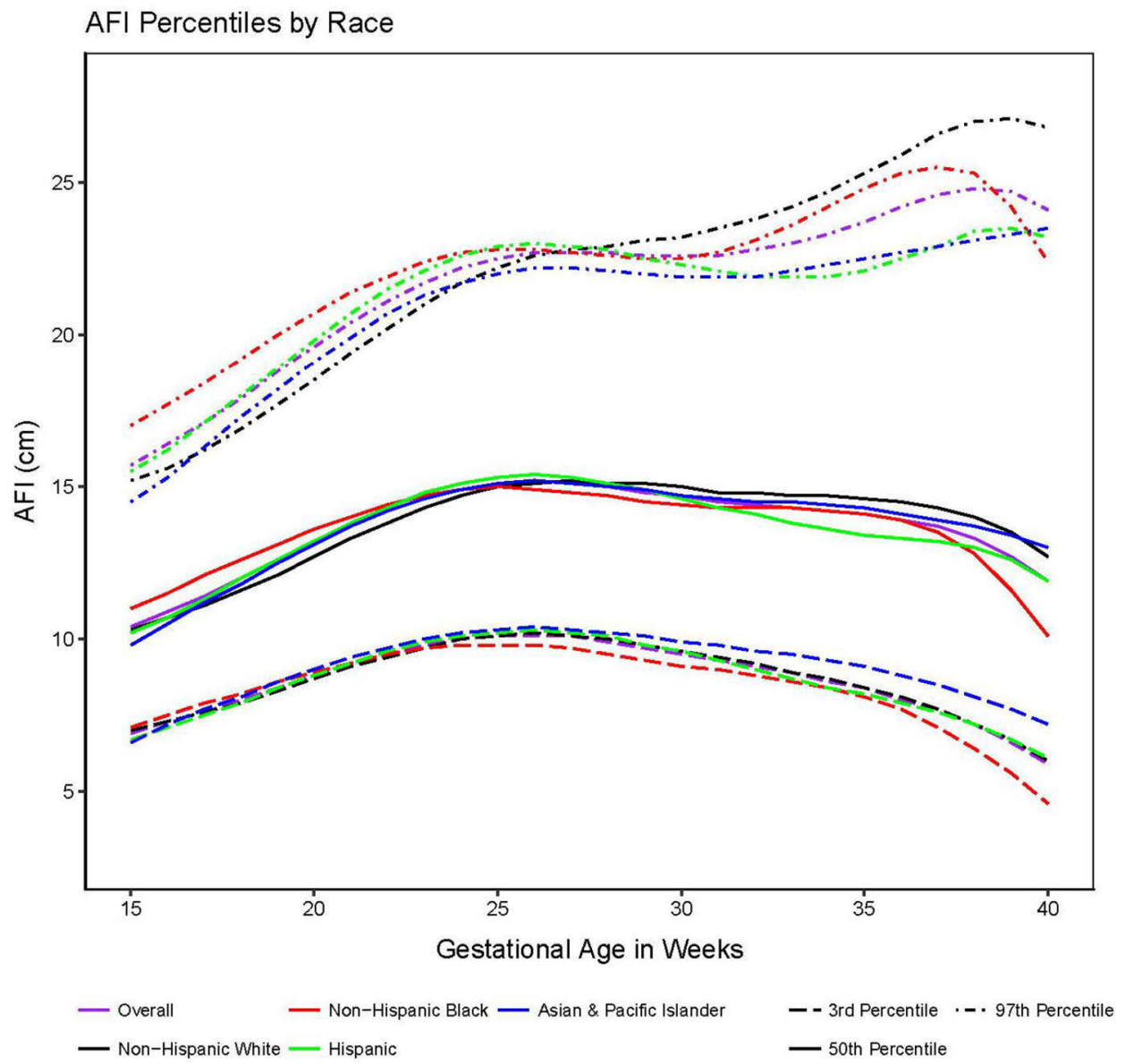

Fig 4.

Unadjusted median amniotic fluid index (AFI) values and extreme ( $3^{\text {rd }}$ and $\left.97^{\text {th }}\right)$ percentiles by weeks of gestation, overall and by race-ethnicity. 


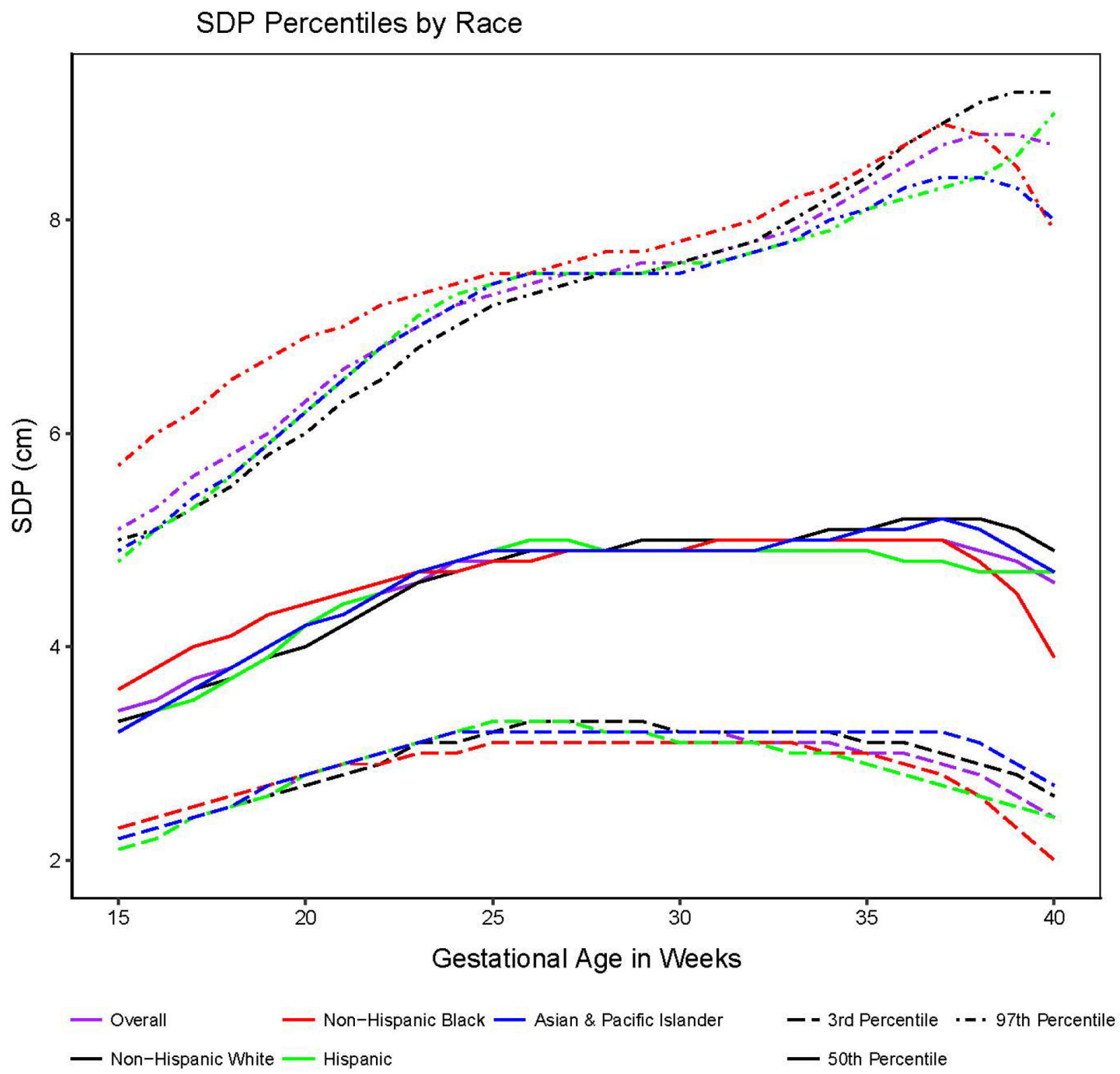

Fig 5.

Unadjusted median single deepest pocket (SDP) values and extreme ( $3^{\text {rd }}$ and $97^{\text {th }}$ ) percentiles by weeks of gestation, overall and by race-ethnicity. 


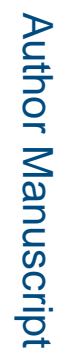

\begin{tabular}{|c|c|c|c|c|c|c|c|c|c|c|c|c|c|c|c|c|c|c|c|c|c|c|c|c|c|}
\hline 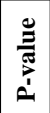 & & $\mid \begin{array}{l}\bar{\delta} \\
\dot{o} \\
\dot{v}\end{array}$ & $\begin{array}{l}\bar{\delta} \\
\dot{v}\end{array}$ & $\begin{array}{l}\overrightarrow{8} \\
\dot{\sigma} \\
v\end{array}$ & $\begin{array}{l}\overline{8} \\
\dot{\sigma}\end{array}$ & $\begin{array}{l}\bar{\delta} \\
\dot{v} \\
\dot{v}\end{array}$ & & & & $\begin{array}{l}\bar{a} \\
\stackrel{0}{0} \\
\text { ?. }\end{array}$ & & & $\begin{array}{l}\text { tै } \\
\stackrel{0}{0}\end{array}$ & $\begin{array}{l}\bar{\Xi} \\
\vdots \\
\dot{v}\end{array}$ & $\begin{array}{l}\overline{\tilde{\sigma}} \\
\stackrel{0}{0}\end{array}$ & $\begin{array}{l}\bar{\delta} \\
\dot{\delta} \\
v\end{array}$ & & & $\begin{array}{l}\bar{\delta} \\
\dot{o} \\
\dot{v}\end{array}$ & & & & & & $\bar{\varnothing}$ \\
\hline ‡ & $\begin{array}{l}2 \\
\underline{B} \\
\text { II } \\
z\end{array} \mid$ & 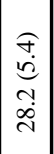 & 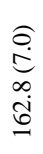 & 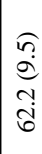 & 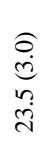 & & $\therefore$ & 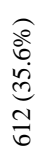 & 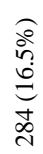 & & 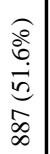 & 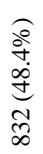 & 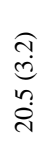 & 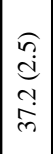 & $\begin{array}{l}\stackrel{o}{\ominus} \\
\stackrel{v}{n} \\
\dot{m}\end{array}$ & & 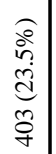 & 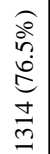 & & 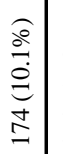 & 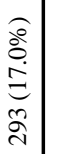 & 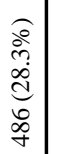 & 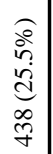 & 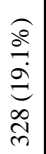 & \\
\hline
\end{tabular}

롤

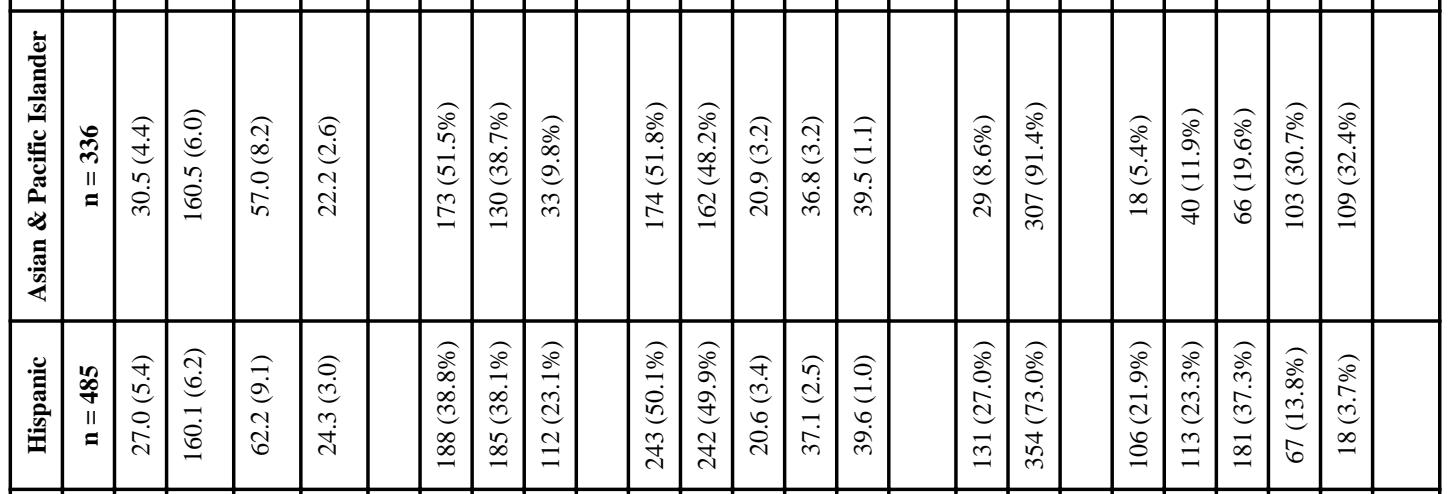

递

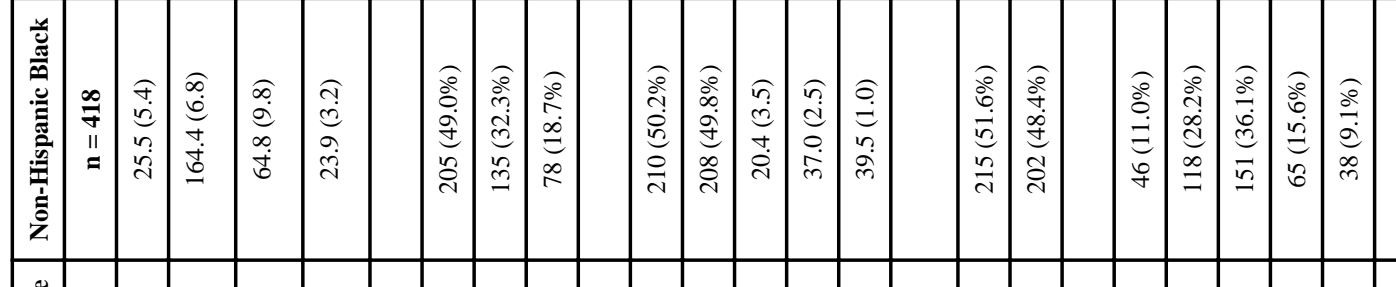

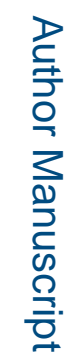

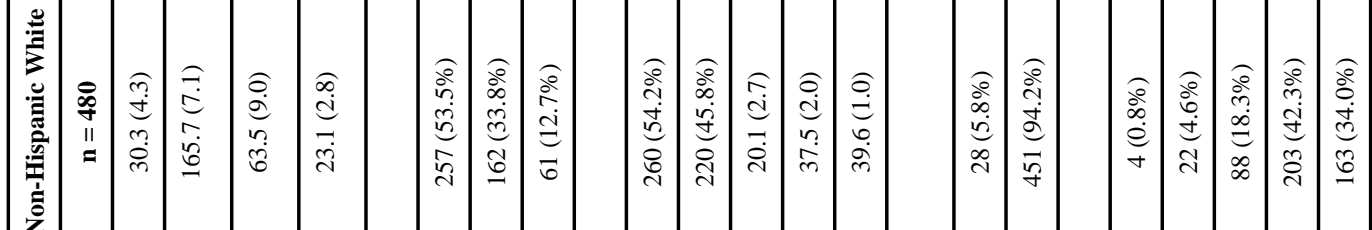

공

$\frac{9}{2}$
$\frac{0}{0}$

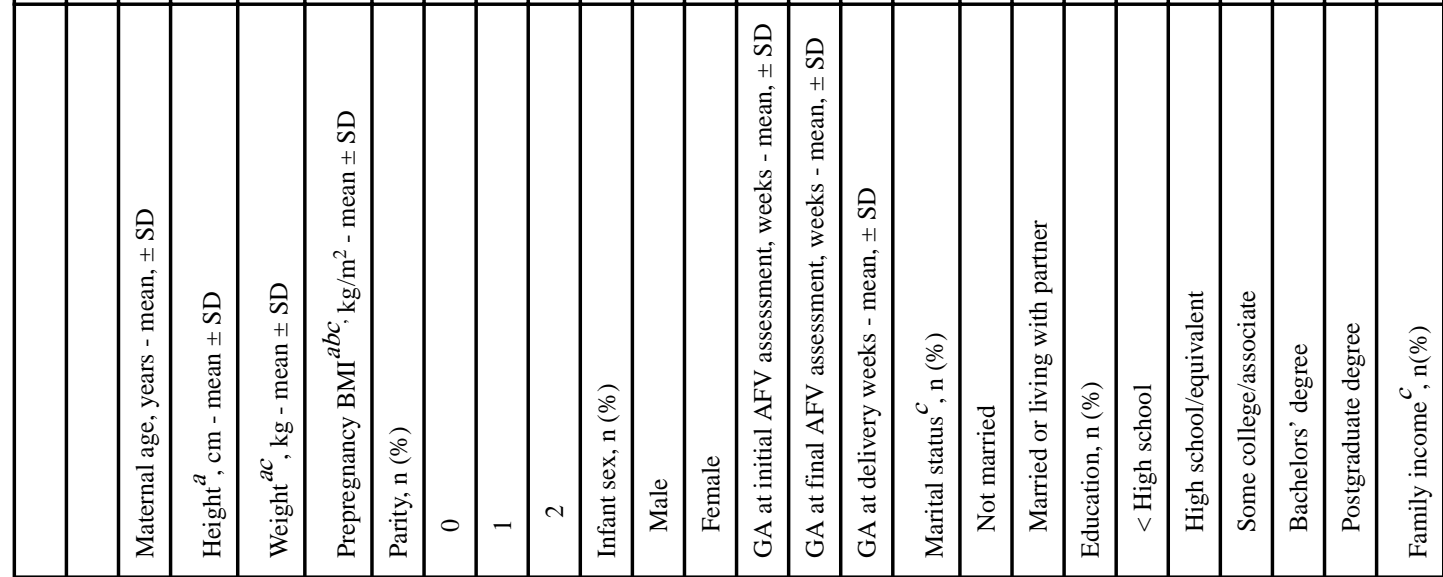

Am J Obstet Gynecol. Author manuscript; available in PMC 2020 July 01. 

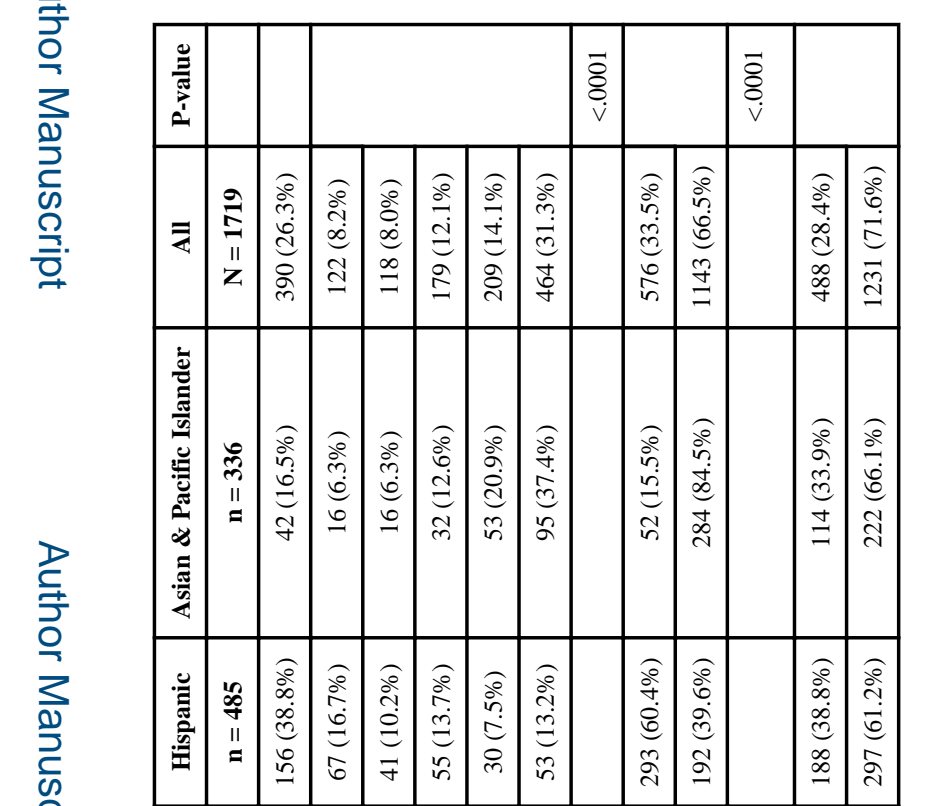

훌
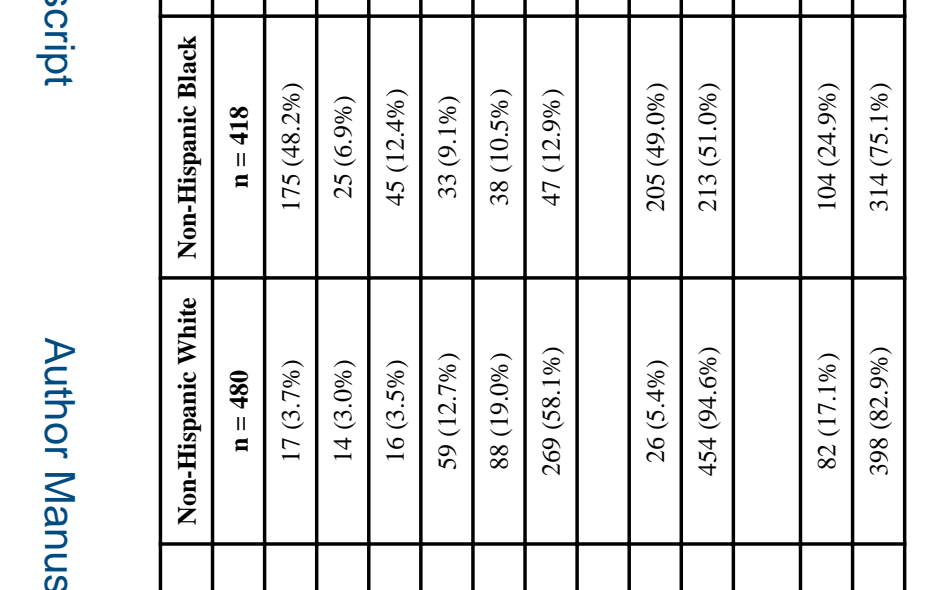

象

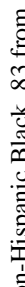

产

号

20

ఏ్

กั 
Table 2.

Unadjusted population percentiles for amniotic fluid index $(\mathrm{cm})$ by gestational age in normal pregnancies

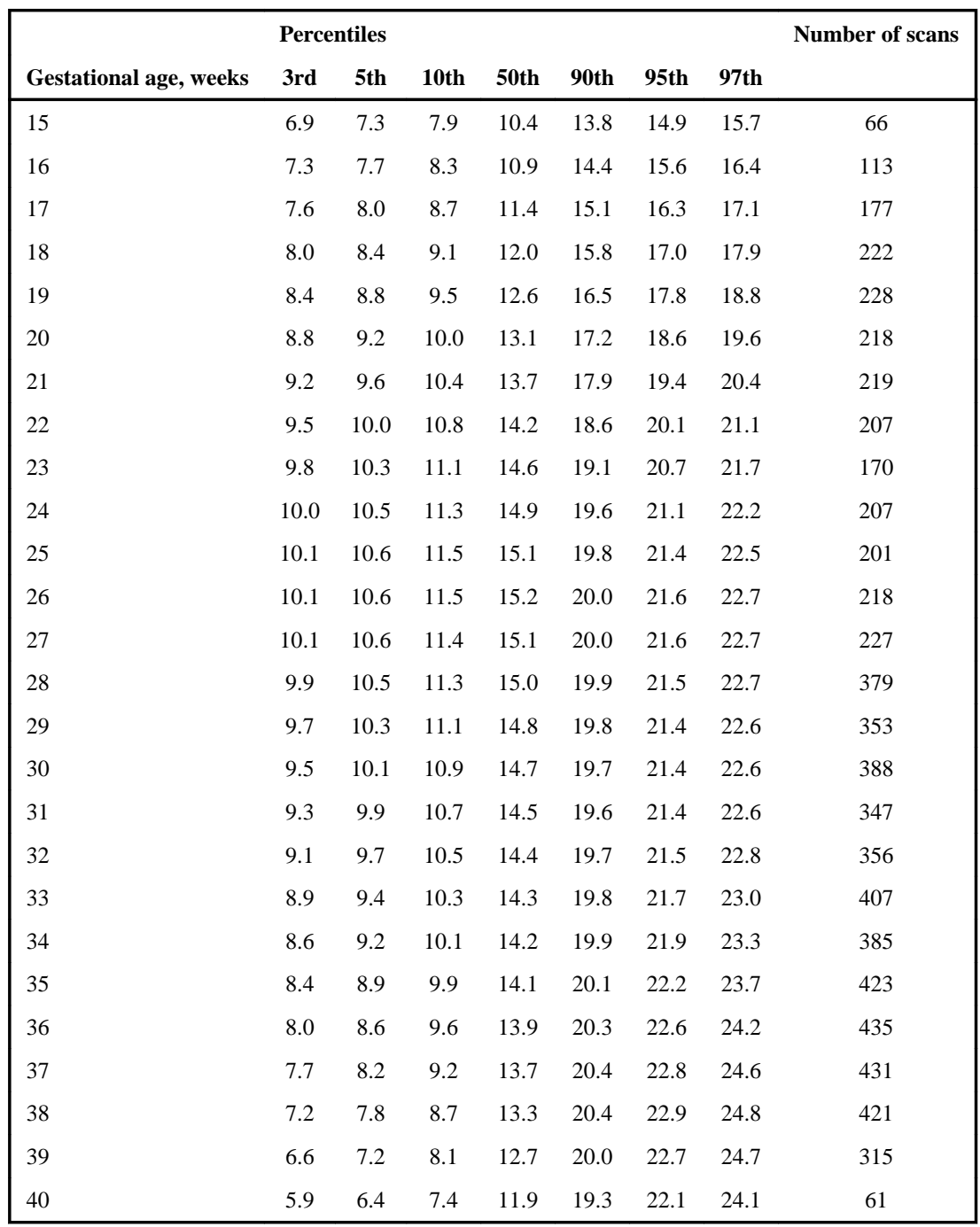


Table 3.

Unadjusted population percentiles for single deepest pocket $(\mathrm{cm})$ by gestational age in normal pregnancies.

\begin{tabular}{|c|c|c|c|c|c|c|c|c|}
\hline \multirow[b]{2}{*}{ Gestational age, weeks } & \multicolumn{7}{|c|}{ Percentile } & \multirow[t]{2}{*}{ Number of scans } \\
\hline & 3rd & 5th & 10th & 50th & 90th & 95th & 97th & \\
\hline 15 & 2.2 & 2.3 & 2.5 & 3.4 & 4.5 & 4.9 & 5.1 & 66 \\
\hline 16 & 2.3 & 2.4 & 2.6 & 3.5 & 4.7 & 5.1 & 5.3 & 113 \\
\hline 17 & 2.4 & 2.5 & 2.8 & 3.7 & 4.9 & 5.3 & 5.6 & 177 \\
\hline 18 & 2.5 & 2.7 & 2.9 & 3.8 & 5.1 & 5.5 & 5.8 & 222 \\
\hline 19 & 2.6 & 2.8 & 3.0 & 4.0 & 5.3 & 5.7 & 6.0 & 228 \\
\hline 20 & 2.8 & 2.9 & 3.1 & 4.2 & 5.5 & 6.0 & 6.3 & 218 \\
\hline 21 & 2.9 & 3.0 & 3.3 & 4.3 & 5.7 & 6.2 & 6.6 & 219 \\
\hline 22 & 3.0 & 3.1 & 3.4 & 4.5 & 6.0 & 6.5 & 6.8 & 207 \\
\hline 23 & 3.1 & 3.2 & 3.5 & 4.6 & 6.2 & 6.7 & 7.0 & 170 \\
\hline 24 & 3.1 & 3.3 & 3.6 & 4.8 & 6.3 & 6.8 & 7.2 & 207 \\
\hline 25 & 3.2 & 3.4 & 3.7 & 4.8 & 6.4 & 7.0 & 7.3 & 201 \\
\hline 26 & 3.2 & 3.4 & 3.7 & 4.9 & 6.5 & 7.1 & 7.4 & 218 \\
\hline 27 & 3.2 & 3.4 & 3.7 & 4.9 & 6.6 & 7.1 & 7.5 & 227 \\
\hline 28 & 3.2 & 3.4 & 3.7 & 4.9 & 6.6 & 7.1 & 7.5 & 379 \\
\hline 29 & 3.2 & 3.4 & 3.7 & 4.9 & 6.6 & 7.2 & 7.6 & 353 \\
\hline 30 & 3.2 & 3.4 & 3.7 & 4.9 & 6.6 & 7.2 & 7.6 & 388 \\
\hline 31 & 3.2 & 3.3 & 3.6 & 4.9 & 6.7 & 7.3 & 7.7 & 347 \\
\hline 32 & 3.1 & 3.3 & 3.6 & 4.9 & 6.7 & 7.4 & 7.8 & 356 \\
\hline 33 & 3.1 & 3.3 & 3.6 & 5.0 & 6.8 & 7.5 & 7.9 & 407 \\
\hline 34 & 3.1 & 3.3 & 3.6 & 5.0 & 7.0 & 7.6 & 8.1 & 385 \\
\hline 35 & 3.0 & 3.2 & 3.6 & 5.0 & 7.1 & 7.8 & 8.3 & 423 \\
\hline 36 & 3.0 & 3.2 & 3.5 & 5.0 & 7.2 & 8.0 & 8.5 & 435 \\
\hline 37 & 2.9 & 3.1 & 3.4 & 5.0 & 7.3 & 8.1 & 8.7 & 431 \\
\hline 38 & 2.8 & 3.0 & 3.3 & 4.9 & 7.3 & 8.2 & 8.8 & 421 \\
\hline 39 & 2.6 & 2.8 & 3.2 & 4.8 & 7.2 & 8.1 & 8.8 & 315 \\
\hline 40 & 2.4 & 2.6 & 2.9 & 4.6 & 7.1 & 8.0 & 8.7 & 61 \\
\hline
\end{tabular}

